\title{
INVESTIGAÇÃO DO PERFIL DOS ARTIGOS PUBLICADOS NOS CONGRESSOS DE CONTABILIDADE DA USP E DA UFSC COM ÊNFASE NA INICIAÇÃO CIENTÍFICA
}

\author{
SANDRA ROLIM ENSSLIN \\ Doutora em Engenharia de Produção pela \\ Universidade Federal de Santa Catarina \\ Professora Adjunta da Universidade Federal de Santa Catarina \\ E-mail: sensslin@gmail.com
}

\author{
BEATRIZ MAURILIA DOS SANTOS DA SILVA \\ Graduada em Ciências Contábeis pela \\ Universidade Federal de Santa Catarina \\ E-mail: beatriz.bmss@gmail.com
}

\begin{abstract}
Resumo
Este artigo tem por objetivo analisar os artigos publicados nos anais dos Congressos USP de Controladoria e Contabilidade e Iniciação Científica em Contabilidade (2004) e compará-los com a produção dos Congressos UFSC de Controladoria e Finanças e Iniciação Científica em Contabilidade (2007). Esta pesquisa, de caráter descritivo, a partir de um estudo bibliométrico, busca descrever as características dessas publicações que contemplam a modalidade "Iniciação Científica". Os resultados evidenciaram que: prevalecem os estudos empírico-teóricos; se sobressaem as referências nacionais; os livros são as obras mais referenciadas; há excesso de autores por artigos nos Congressos UFSC; a maioria dos autores possui Pós-graduação; a maior parte dos autores pertence às regiões Nordeste, Sudeste e Sul; as IES com maior participação de autores são a UFSC, a USP e a UFPE; a produtividade dos autores da amostra é menor do que a prevista pela Lei de Lotka; e o macro-tema Contabilidade Gerencial é o mais explorado pelos autores mais prolíficos.
\end{abstract}

Palavras-chave: análise da produção científica; bibliometria; congressos de contabilidade; iniciação científica.

\begin{abstract}
This paper has as an objective analyze the articles published in the Annais of University of São Paulo's [USP] Congresses of Controllership and Accounting and of Accounting Scientific Initiation (2004) and compare them to the articles published in the Annais of Santa Catarina's Federal University [UFSC] Congresses of Controllership and Finances and Accounting Scientific Initiation (2007). This research has a descriptive character and is based on a bibliometric study. It seeks to describe the characteristics of these publications that range "Scientific Initiation" condition. The results evidence that: empiric-theoretic studies prevail; national reference is prominent; books are the most referred works; there is excess of authors per article on UFSC's Congresses; most part of the authors have graduation course and are from Northeast, Southeast and South regions; the universities that contribute with the major part of authors are UFSC, USP and UFPE [Pernambuco Federal University]; the productivity of the authors of the sample is shorter than the productivity foreseen by Lotka Law; and the Managerial Accounting theme is the most explored by the most prolific authors.
\end{abstract}

Key words: scientific production analyses, bibliometry, accounting congresses, scientific initiation. 


\section{INTRODUÇÃO}

As pesquisas em geral contribuem para a produção e disseminação do conhecimento científico em diferentes áreas do conhecimento. Dessa forma, as produções científicas em contabilidade representam um importante referencial teórico, visto que, nessas pesquisas são abordados temas relevantes do contexto nacional e internacional. Além disso, as abordagens atuais em contabilidade proporcionam uma literatura atual e de referência para a ciência contábil. Os congressos, seminários, simpósios, fóruns e eventos científicos desenvolvidos nas comunidades acadêmicas incentivam a produção do conhecimento. Nesse contexto, as universidades passam a estimular a iniciação científica dos estudantes, promovendo a comunicação científica por meio desses eventos.

Com o propósito de desenvolver a aprendizagem de pesquisa, o Departamento de Contabilidade e Atuária da Faculdade de Economia, Administração e Contabilidade (FEA) da Universidade de São Paulo (USP) lançou, em 2004, paralelamente ao $4^{\circ}$ Congresso de Controladoria e Contabilidade (CCC-USP), o $1^{\circ}$ Congresso USP de Iniciação Científica em Contabilidade (CIC-USP), sob a coordenação geral do Prof. Dr. Valmor Slomski. Em 2007, o Departamento de Ciências Contábeis da Universidade Federal de Santa Catarina (UFSC), promoveu o $1^{\circ}$ Congresso UFSC de Iniciação Científica em Contabilidade (CIC-UFSC), juntamente com $01^{\circ}$ Congresso UFSC de Controladoria e Finanças (CCF-UFSC) sob a coordenação geral do Prof. Dr. Ernesto Fernando Rodrigues Vicente.

Esses eventos, sediados por seus departamentos de contabilidade, representam "um espaço privilegiado para que os alunos de graduação exercitem a atividade de pesquisa científica em Contabilidade, bem como na preparação, exposição e debate de seus trabalhos junto a um seleto público" (FEA-USP, 2008, p.). Cabe ressaltar, todavia, a necessidade de acompanhar o andamento dessas publicações por meio de técnicas que permitam a identificação das características e as tendências dessas produções.

Alguns estudos sobre o levantamento da produção científica em contabilidade aplicam as abordagens bibliométricas na investigação e avaliação da produção científica; dentre eles destacam-se os artigos de Cardoso, Mendonça Neto, Riccio e Sakata (2005), Leite Filho (2006), Cabral dos Santos e Ensslin (2007). Esta pesquisa foi motivada pelo trabalho desenvolvido por Gomes et al. (2007), que analisou a produção científica dos três primeiros anos do Congresso USP de Iniciação Científica em Contabilidade, com o objetivo de traçar um perfil da produção científica publicada nesse congresso nos anos de 2004 a 2006.

No intuito de ampliar o estudo de Gomes et al. (2007), o presente trabalho propõe investigar a produção científica do $1^{\circ}$ Congresso UFSC de Controladoria e Finanças, do $1^{\circ}$ Congresso UFSC de Iniciação Científica em Contabilidade, do $4^{\circ}$ Congresso USP de Controladoria e Contabilidade, servindo-se do levantamento do $1^{\circ}$ Congresso USP Iniciação Científica em Contabilidade iniciado. A escolha dos eventos a serem investigados baseou-se no fato de que eles são voltados para a área de contabilidade, sediados por instituições de ensino superior, e, principalmente, porque apresentam a modalidade "Iniciação Científica”.

Diante do exposto emerge a pergunta de pesquisa: qual o perfil das produções científicas nos congressos de contabilidade sediados pelos Departamentos de Contabilidade da USP e da UFSC? Esta pesquisa tem com objetivo geral sistematizar as publicações dos Congressos USP de Controladoria e Contabilidade e Iniciação Científica em Contabilidade (2004) e compará-la com a produção dos Congressos UFSC de Controladoria e Finanças e Iniciação Científica em Contabilidade (2007). Utilizando a análise bibliométrica, buscar-se-á alcançar os seguintes objetivos específicos: (i) computar o número de páginas por artigo; (ii) distribuir os artigos quanto à tipologia de pesquisa adotada; (iii) classificar 
os artigos por macro-temas abordados; (iv) apontar o número e (v) os tipos de referências utilizadas; (vi) investigar o número de autores por artigo; (vii) apresentar a frequiência dos autores por gênero; (viii) verificar a titulação acadêmica e a (ix) localização institucional dos autores; (x) identificar o ranking dos autores por IES (instituições de ensino superior); (xi) analisar a produtividade dos autores mediante a Lei Bibliométrica de Lotka; e (xii) investigar os autores mais prolíficos.

Os resultados deste estudo poderão ser úteis para alunos, professores, pesquisadores, profissionais da área contábil e interessados na produção científica desse campo do conhecimento, visto que são oportunidades de se conhecer as abordagens atuais em contabilidade, além das características dessas produções.

\section{METODOLOGIA}

\subsection{ENQUADRAMENTO METODOLÓGICO}

O estudo caracteriza-se como uma pesquisa descritiva. A pesquisa descritiva, de acordo com Andrade (2002 apud BEUREN, 2006, p. 81), "preocupa-se em observar os fatos, registrá-los, analisá-los, classificá-los e interpretá-los, e o pesquisador não interfere neles". Neste estudo, busca-se descrever as características das publicações, de seus autores e estabelecer relações entre as variáveis mapeadas. A abordagem da pesquisa é quantitativa e qualitativa. Para Richardson (1999), a pesquisa quantitativa depende da utilização de instrumental estatístico como base no processo de análise do problema, enquanto "a metodologia qualitativa fornece análise mais detalhada sobre as investigações, hábitos, atitudes, tendências de comportamento etc" (MARCONI \& LAKATOS, 2007 , p. 269). A pesquisa utiliza a análise quantitativa dos dados quando investiga o número de páginas por artigo; o número de referências por artigo; o número de autores; e o ranking dos autores por IES. Já a abordagem qualitativa é utilizada quando se analisa a tipologia de pesquisa adotada; os macro-temas abordados; o tipo de referência utilizada nos artigos; o gênero; a titulação acadêmica; a localização institucional dos autores; e os autores mais prolíficos. A análise é considerada quantitativa-qualitativa quando da aplicação da Lei de Lotka.

No que se refere aos procedimentos utilizados, trata-se de uma pesquisa de levantamento de dados ou survey, pois pretende "descrever com exatidão algumas características da população designada" (TRIPODI; FELLIN; MEYER, 1981, p. 39 apud BEUREN, 2006, p. 85). Ou seja, por meio de técnicas bibliométricas pretende-se sistematizar as publicações dos quatro congressos que compõem a amostra desta pesquisa. A fonte de dados da pesquisa é de natureza secundária e encontra-se nos anais dos Congressos UFSC, realizados em setembro de 2007 e nos anais dos Congressos USP, de outubro de 2004. Essa seleção de amostra caracteriza-se como intencional e nãoprobabilística, de modo que os resultados não podem ser generalizados para toda a população, pois sua validade se restringe ao contexto específico que foi pesquisado (OLIVEIRA, 2003).

\subsection{BIBLIOMETRIA COMO INSTRUMENTO DE INTERVENÇÃO}

Até a década de 60 os estudos bibliométricos eram conhecidos como "bibliografia estatística" (termo cunhado por Edward Wyndham Hulme, em 1922). Em 1969, Alan 
Pritchard popularizou o uso do termo Bibliometria (VANTI, 2002). Pritchard (1969), citado por Bufrem e Prates (2005, p. 11), conceituou essa metodologia como "a aplicação de métodos matemáticos e estatísticos a livros e outros meios de comunicação, aconselhando sua utilização em todos os estudos que buscassem quantificar o processo de comunicação escrita". Por sua vez, Macedo dos Santos (2003, p. 29) argumenta que "os dados quantitativos são calculados a partir de contagens estatísticas das publicações ou de elementos extraídos das mesmas". Bufrem e Prates (2005) julgam que pelo estudo das publicações, tem-se a possibilidade de conhecer o desenvolvimento de uma determinada área da ciência, numa região específica, observando temáticas, materiais ou períodos específicos.

Optou-se, neste trabalho, por aplicar as abordagens bibliométricas e, especialmente, a Lei de Lotka, visto que essa lei é a mais utilizada nos estudos que focam a produção científica em contabilidade. A Lei de Lotka, também conhecida como Lei do Quadrado Inverso, "aponta para a medição da produtividade dos autores, mediante um modelo de distribuição tamanho-freqüência dos diversos autores em um conjunto de documentos" (VANTI, 2002, p. 153). Alvarado (2002) ensina que o número de autores que publicam $n$ artigos em um determinado campo científico é aproximadamente $1 / n^{2}$ daqueles que publicam um único artigo, e que a proporção daqueles que publicam apenas um artigo é aproximadamente $60 \%$. Chung e Cox (1990), citados por Leal, Oliveira e Soluri (2003, p. 95), explicam que "o número de autores com um único trabalho publicado, segundo a Lei de Lotka, deveria ser de $6 / \pi^{2}$, que resulta numa constante igual a $60,8 \%$ dos autores". Assim, o número de autores que publicam dois artigos é igual a 1/4 do número de autores que publicam um artigo, ou 15,2\%; o número de autores que publicam três artigos é igual a $1 / 9$ dos que publicam um artigo, ou 6,8\%, e assim por diante (LEAL, OLIVEIRA e SOLURI, 2003). Ainda de acordo com os autores, a Lei de Lotka generalizada é $a_{n}=a_{1} / n^{c}$, na qual $a_{n}$ é o número de autores com $n$ artigos, $a_{1}$ é o número de autores com um artigo, $n$ é o número de artigos e c é o coeficiente generalizado da Lei de Lotka. Essa lei supõe que alguns pesquisadores de uma determinada área do conhecimento publicam muito, enquanto muitos pesquisadores publicam poucos artigos (VOOS, 1974 apud GUEDES e BORSCHIVER, 2005).

\subsection{PROCEDIMENTOS PARA COLETA E ANÁLISE DOS DADOS}

Os Congressos USP (2004) apresentaram 120 artigos, 100 artigos do CCC-USP e 20 artigos do CIC-USP, disponibilizados no site do evento
(www.congressoeac.locaweb.com.br). Já os artigos dos Congressos UFSC (2007) totalizaram 71 publicações, 45 artigos do CCF-UFSC e 26 do CIC-UFSC, e foram disponibilizados em CD-ROM aos participantes do evento. Os totais de artigos analisados somam 191 publicações, que correspondem à fonte de coleta de dados desta pesquisa. Destaca-se que alguns dados referentes aos 20 artigos do $1^{\circ}$ Congresso USP de Iniciação Científica já foram levantados por Gomes et al. (2007), tais como: (i) o número de páginas por artigo; (ii) a tipologia de pesquisa adotada; (iii) os macro-temas abordados; (iv) o número de referências por artigo; (v) os tipos de referências utilizadas nos artigos; (vi) o número de autores por artigo; (vii) o gênero; (viii) a titulação acadêmica; e a (ix) localização institucional dos autores. Esta pesquisa expandiu o trabalho de Gomes et al. (2007) ao incluir no estudo a investigação do $4^{\circ}$ Congresso USP de Controladoria e Contabilidade, por ter inaugurado $01^{\circ}$ Congresso USP de Iniciação Científica. Foram incluídos, também, os trabalhos do $1^{\circ}$ Congresso UFSC de Controladoria e Finanças e do $1^{\circ}$ Congresso UFSC de Iniciação Científica em Contabilidade. Além disso, a atual pesquisa levantou (x) o ranking dos autores por IES; (xi) a produtividade com base na Lei de Lotka; bem como (xii) os autores mais prolíficos. 
Observa-se que os artigos, em sua maioria, constituíram-se como fonte de coleta de dados. Entretanto, cabe explicar, resumidamente, os procedimentos para a coleta e análise de cada elemento investigado nos quatro congressos analisados: (i) Número médio de páginas por artigo: os quatro congressos exigem o mínimo de dez e o máximo de quinze páginas para cada artigo. Neste tópico, contou-se simplesmente o número de páginas que continha cada artigo e calculou-se a média de páginas por artigo; (ii) Tipologia de pesquisa utilizada: foram considerados três tipos de estudos, cuja classificação respalda-se na proposta vinculada por Martins (2002) e adotada por Gomes et al. (2007; (iii) Macro-temas abordados: foi considerada a classificação temática e assuntos evidenciados no Quadro 1, cuja elaboração foi desenvolvida por Oliveira (2002). A pesquisa atual se concentrou nessa classificação temática, porém, incluiu assuntos por ela não contemplados, tais como: Finanças Corporativas, Mercado Financeiro e de Crédito no macro-tema Contabilidade e Mercado de Capital, bem como Balanced ScoreCard, Capital Intectual, Governança Corporativa, Target Costing e Teoria das Restrições no macro-tema Contabilidade Gerencial. Cabe ressaltar que esses assuntos não foram incluídos no item 17 ("Outros"), porque tais assuntos estão ligados a alguns macro-temas citados no Quadro 1, sendo inadequado incluí-los no item 17, que foi criado por Oliveira (2002) para a inclusão de assuntos "não cobertos nos temas anteriores". 


\section{CLASSIFICAČ̃O TEMÁTICA E ASSUNTO}

1 Contabilidade e Mercado de Capital - Influência das Demonstrações Contábeis no Mercado de Capitais e na variação no preço das ações.

Educação e Pesquisa Contábil - currículos; métodos de ensino; metodologia de pesquisa;

2 recursos materiais utilizados; formação dos docentes; as dificuldades do ensino prático; aproveitamento de disciplinas; concurso vestibular para ciências contábeis; aspectos relativos à formação do contador como educação continuada; pós-graduação.

Contabilidade para Empresas em Tipos Específicos de Atividades - aspectos contábeis específicos em entidades imobiliárias; cooperativas; agropecuárias.

Contabilidade para Tipos Específicos de Organizações - aspectos contábeis e fiscais

4 referentes a pequenas e médias empresas; joint venture; sociedades em conta de participação; sociedades sem fins lucrativos não governamentais.

História da Contabilidade - surgimento, desenvolvimento e tendências da contabilidade,

5 evolução do ensino formal da contabilidade e da literatura contábil, no Brasil e no restante do mundo.

Teoria da Contabilidade - epistemologia da contabilidade; princípios e normas contábeis;

6 aspectos teóricos, conceituais e doutrinários relativos a ativo, passivo, receita, despesa, patrimônio, lucro, valor.

Auditoria Externa e Interna - prestação de serviços de auditoria, integração dos serviços de

7 auditoria interna e externa; o planejamento do trabalho de auditoria e a avaliação dos riscos inerentes; relatórios de auditoria; controle de qualidade dos serviços de auditoria.

Contabilidade de Custos - métodos de custeio; a cientificidade da contabilidade de custos; a

8 utilidade e validade do instrumental da contabilidade de custos; a contabilidade de custos no moderno ambiente empresarial; custos da qualidade.

Contabilidade Financeira - aspectos relativos à elaboração e evidenciação das Demonstrações Contábeis, envolvendo: normas contábeis e fiscais, ajustes de fim-deexercício, inventário, equivalência patrimonial, consolidação, reavaliação de ativos,

9 retificações do Balanço Patrimonial, provisionamentos, livros contábeis e fiscais, aspectos conceituais e práticos da correção monetária integral das demonstrações contábeis; reconhecimento da variação do poder aquisitivo; conversão das demonstrações contábeis para moeda estrangeira.

10 Perícia Contábil - avaliação dos fundos de comércio, fraudes, falências, concordatas. Contabilidade Internacional - comparação das diferentes normas e princípios que norteiam a

11 contabilidade nos diversos países do mundo; harmonização das normas e princípios contábeis dos países latino-americanos e do mundo; globalização da economia; mediação e arbitragem.

Contabilidade Gerencial - análise de custos, orçamento empresarial, gestão estratégica de custos, sistemas de informações gerenciais, administração financeira, preço de transferência,

12 avaliação de desempenho, padrões, métodos quantitativos aplicados à contabilidade; custo de oportunidade, análise das demonstrações contábeis, fixação do preço de venda, controladoria.

Exercício Profissional - aspectos referentes ao exercício profissional, como mercado privativo de trabalho, fixação de honorários, contratação dos serviços, responsabilidades do contratado e contratante, sigilo, responsabilidades por perdas e danos causados a terceiros,

13 contratação através de licitações; empresas prestadoras de serviços contábeis - a administração, o uso da informática e o gerenciamento dos custos; aspectos da ética profissional; exame de suficiência; organização sindical; responsabilidade pela edição de normas de contabilidade e auditoria.

Contabilidade Pública, Orçamento Público e Finanças Públicas - objetivos básicos; controle

14 interno; controle do patrimônio público; enfoque gerencial na administração pública; estrutura organizacional e relatórios de órgãos públicos; reforma fiscal.

15 Contabilidade Social e Ambiental - balanço social; contabilidade do meio ambiente; contabilidade de recursos humanos.

16 Contabilidade Tributária - planejamento tributário; regras fiscais versus princípios e normas contábeis.

Outros - aspectos contábeis referentes a processos de privatização; cálculos atuariais; e outros assuntos não cobertos nos temas anteriores.

Quadro 1 - Classificação Temática e Assunto (OLIVEIRA, 2002) 
(iv) Número médio de referências por artigo: as referências foram divididas em nacionais e internacionais. Deve-se destacar que dentro da classificação internacional incluíram-se as obras traduzidas; (v) Tipo de referência utilizada: a seleção do tipo de referência foi desenvolvida conforme a proposta de Cardoso, Pereira e Guerreiro (2004), adaptada por Gomes et al. (2007). Para esta análise, classificaram-se as referências em três categorias: conservadora (livros e normas), intermediária (periódicos Qualis/Capes) e contemporânea (teses, dissertações e monografias; anais de eventos científicos; sites da internet; jornais e revistas; e outros tipos de bibliografias); (vi) Número de autores por artigo: nos Congressos UFSC e USP de Controladoria, cada trabalho pode ter no máximo quatro autores, já o de Iniciação Científica pode ter no máximo seis autores por artigo. Nessa classificação, foi verificado o número de autores em cada artigo, o que também possibilitou identificar o número de participações e de autores em cada congresso. Com isso, todas as características de autoria foram levantadas com base na quantidade de autores e não de participações dos autores. Para essa análise, foi refeita a contagem dos autores da pesquisa de Gomes et al. (2007), a qual havia considerado o número de participações e não o de autores; (vii) Freqüência de autores por gênero: nesse item, verificou-se a freqüência do gênero feminino e masculino entre os autores dos congressos; (viii) Titulação dos autores: esse levantamento ficou limitado aos autores que possuíam o currículo cadastrado na Plataforma Lattes no site do CNPq (Conselho Nacional de Desenvolvimento Científico e Tecnológico). A titulação foi investigada no site (http://buscatextual.cnpq.br ) utilizando o nome do autor na ferramenta de busca dessa plataforma. Os autores não cadastrados foram classificados na categoria de titulação "não informada"; (ix) Localização institucional dos autores: os artigos dos Congressos USP apresentaram no cabeçalho do texto o nome do autor e a instituição de ensino a qual pertence. Dessa forma, foi consultada a Unidade Federativa (UF) no endereço eletrônico da instituição na internet. As informações referentes à localidade institucional dos autores dos Congressos UFSC não estavam disponíveis no site do evento, na ocasião da coleta de dados, de modo que essas informações foram coletadas junto ao departamento de Ciências Contábeis, diretamente na base de dados dos congressos; (x) Ranking dos autores por IES: foram elencadas as instituições que tiveram o maior número de participação nos quatro congressos; (xi) Aplicação da Lei de Lotka: foi levantada a freqüência de artigos por autor e fez-se a comparação com o Padrão de Lotka; e (xii) Autores mais prolíficos: nesse item, verificaram-se os autores que produziram maior número de artigos e os macro-temas com os quais contribuíram. O levantamento dos itens supracitados foi organizado em planilhas do Microsoft Office Excel, o que possibilitou a sua classificação e contagem e, posteriormente, a sistematização em tabelas e gráficos.

\section{DESCRIÇÃO E ANÁLISE DOS DADOS}

Dentre os 191 artigos analisados, 120 pertencem aos Congressos USP e 71 aos Congressos UFSC. A partir dos dados dessas publicações, apresentam-se os resultados.

(i) Número de páginas: a Tabela 1 relaciona o número total de páginas por congresso e o número médio de páginas por artigo, em cada congresso. 
Tabela 1 - Número médio de páginas por artigo nos Congressos USP e UFSC

\begin{tabular}{l|c|c|c|c|}
\multirow{2}{*}{ Páginas } & \multicolumn{2}{|c|}{$\begin{array}{c}\text { Congressos USP } \\
\text { (2004) }\end{array}$} & \multicolumn{2}{c}{$\begin{array}{c}\text { Congressos UFSC } \\
\text { (2007) }\end{array}$} \\
\cline { 2 - 5 } & CCC & CIC & CCF & CIC \\
\hline (a) Número de páginas & 1.479 & 284 & 606 & 350 \\
\hline (b) Número de artigos & 100 & 20 & 45 & 26 \\
\hline $\begin{array}{l}\text { (a/b) Número médio de } \\
\text { páginas }\end{array}$ & 14,8 & 14,2 & 13,5 & 13,5 \\
\end{tabular}

Fonte: Adaptado de GOMES et al.(2007).

Verifica-se que os autores dos Congressos USP aproveitaram mais o limite disponível, conforme o cálculo do número médio de páginas, resultando em aproximadamente 15 páginas no CCC-USP e 14 no CIC-USP. De acordo com a Tabela 1, os Congressos UFSC apresentaram uma média inferior, de aproximadamente 13 páginas por artigo.

(ii) Tipologia de pesquisa: a Tabela 2 apresenta os tipos de pesquisa adotados nos trabalhos.

Tabela 2 - Tipologia de pesquisa aplicada nos artigos dos Congressos USP e UFSC

\begin{tabular}{|l|c|c|c|c|c|c|c|c|}
\hline \multirow{2}{*}{ Tipologia de Pesquisa } & \multicolumn{4}{|c|}{ Congressos USP (2004) } & \multicolumn{4}{c|}{ Congressos UFSC (2007) } \\
\cline { 2 - 10 } & CCC & CIC & \multicolumn{2}{|c|}{ Total } & CCF & CIC & \multicolumn{2}{|c|}{ Total } \\
\hline $\begin{array}{l}\text { Exclusivamente } \\
\text { bibliográfica }\end{array}$ & 12 & 2 & 14 & $11,7 \%$ & 7 & 4 & 11 & $15,5 \%$ \\
\hline $\begin{array}{l}\text { Bibliográfica com apoio } \\
\text { de exemplos numéricos }\end{array}$ & 7 & 7 & 14 & $11,7 \%$ & 4 & 1 & 5 & $7,0 \%$ \\
\hline $\begin{array}{l}\text { Empírico-teórica - com } \\
\text { dados primários e/ou } \\
\text { secundários }\end{array}$ & 81 & 11 & 92 & $\mathbf{7 6 , 6 \%}$ & 34 & 21 & 55 & $\mathbf{7 7 , 5 \%}$ \\
\hline Total & 100 & 20 & 120 & $100,0 \%$ & 45 & 26 & 71 & $100,0 \%$ \\
\hline
\end{tabular}

Fonte: Adaptado de GOMES et al.(2007).

Os dados evidenciados mostram que, nos Congressos USP, as pesquisas empíricoteóricas são mais freqüentes, com $76 \%$ de ocorrência. Em seguida, são classificados os estudos exclusivamente bibliográficos e as pesquisas bibliográficas (com apoio de exemplos numéricos), com $12 \%$ cada um. Pode-se observar que, da mesma forma, nos Congressos UFSC, prevalecem os estudos empírico-teóricos, com $77 \%$ de frequiência, seguidos dos estudos exclusivamente bibliográficos, que representam 16\%. Já as pesquisas bibliográficas com apoio de exemplos numéricos correspondem a 7\% dos trabalhos.

(iii) Macro-temas abordados: a Tabela 3 elenca o número de artigos por macro-temas abordados. 
Tabela 3 - Macro-temas abordados nos Congressos USP e UFSC

\begin{tabular}{|c|c|c|c|c|c|c|c|c|}
\hline \multirow{3}{*}{$\begin{array}{l}\text { Macro-Tema } \\
\begin{array}{l}\text { Contabilidade e mercado de } \\
\text { capital }\end{array}\end{array}$} & \multicolumn{4}{|c|}{ Congressos USP (2004) } & \multicolumn{4}{|c|}{ Congressos UFSC (2007) } \\
\hline & \multirow{2}{*}{$\frac{C C C}{29}$} & \multirow{2}{*}{$\frac{\mathrm{CIC}}{1}$} & \multicolumn{2}{|c|}{ Total } & \multirow{2}{*}{$\begin{array}{c}\text { CCF } \\
7\end{array}$} & \multirow{2}{*}{$\frac{\mathrm{CIC}}{2}$} & \multicolumn{2}{|c|}{ Total } \\
\hline & & & 30 & $25,0 \%$ & & & 9 & $12,7 \%$ \\
\hline Educação e pesquisa contábil & 5 & 1 & 6 & $5,0 \%$ & 6 & 9 & 15 & $21,1 \%$ \\
\hline $\begin{array}{l}\text { Contabilidade para empresas } \\
\text { em tipos específicos de } \\
\text { atividades }\end{array}$ & 1 & - & 1 & $0,8 \%$ & 2 & 2 & 4 & $5,6 \%$ \\
\hline $\begin{array}{l}\text { Contabilidade para tipos } \\
\text { específicos de organizações }\end{array}$ & 6 & 1 & 7 & $5,8 \%$ & 1 & - & 1 & $1,4 \%$ \\
\hline História da Contabilidade & - & - & - & - & - & - & - & - \\
\hline Teoria da Contabilidade & 1 & 1 & 2 & $1,7 \%$ & - & - & - & - \\
\hline Auditoria externa e interna & - & - & - & - & - & - & - & - \\
\hline Contabilidade de custos & 3 & 3 & 6 & $5,0 \%$ & - & - & - & - \\
\hline Contabilidade financeira & 9 & 1 & 10 & $8,3 \%$ & 1 & - & 1 & $1,4 \%$ \\
\hline Perícia contábil & - & 1 & 1 & $0,8 \%$ & - & - & - & - \\
\hline Contabilidade internacional & 6 & - & 6 & $5,0 \%$ & 1 & 1 & 2 & $2,8 \%$ \\
\hline Contabilidade gerencial & 21 & 6 & 27 & $22,5 \%$ & 15 & 4 & 19 & $26,8 \%$ \\
\hline Exercício profissional & 4 & - & 4 & $3,4 \%$ & 2 & 1 & 3 & $4,3 \%$ \\
\hline $\begin{array}{l}\text { Contabilidade pública, } \\
\text { orçamento público e finanças } \\
\text { públicas }\end{array}$ & 7 & 1 & 8 & $6,7 \%$ & 2 & - & 2 & $2,8 \%$ \\
\hline $\begin{array}{l}\text { Contabilidade social e } \\
\text { ambiental }\end{array}$ & 7 & - & 7 & $5,8 \%$ & 5 & 6 & 11 & $15,5 \%$ \\
\hline Contabilidade tributária & 1 & 1 & 2 & $1,7 \%$ & 1 & 1 & 2 & $2,8 \%$ \\
\hline Outros & - & 3 & 3 & $2,5 \%$ & 2 & - & 2 & $2,8 \%$ \\
\hline Total & 100 & 20 & 120 & $100,0 \%$ & 45 & 26 & 71 & $100,0 \%$ \\
\hline
\end{tabular}

Fonte: Adaptado de GOMES et al.(2007).

Os resultados relacionados no CCC-USP evidenciam que o macro-tema com maior número de publicações é Contabilidade e Mercado de Capital. Cabe destacar que os Congressos USP apresentaram entre uma de suas áreas temáticas o tema Mercados Financeiros de Créditos e de Capitais, corroborando o percentual de artigos referentes ao macro-tema Contabilidade e Mercado de Capital, que abrangeu as publicações desta área temática. No CIC-USP, o destaque é para o macro-tema Contabilidade Gerencial, com 30\% de freqüência dentre os 20 artigos publicados nesse congresso. Os macro-temas História da Contabilidade e Auditoria Externa e Interna não tiveram artigos publicados nos Congressos USP. Nota-se que, no CCF-UFSC, o macro-tema com maior frequiência de artigos publicados foi Contabilidade Gerencial. Já no CIC-UFSC, o destaque é para o macro-tema Educação e Pesquisa Contábil, com 35\%. Verifica-se que, nos Congressos UFSC, os macro-temas História da Contabilidade, Teoria da Contabilidade, Auditoria Externa e Interna, Contabilidade de Custos e Perícia Contábil não foram abordados.

(iv) Número de referências: a Tabela 4 traz o número de referências nacionais e internacionais, o número total e o número médio de referências por artigo em cada congresso. 
Tabela 4 - Número médio de referências por artigo nos Congressos USP e UFSC

\begin{tabular}{l|cc|c|c|c|c|c|c|}
\multirow{2}{*}{ Referências } & \multicolumn{4}{|c|}{ Congressos USP (2004) } & \multicolumn{3}{c|}{ Congressos UFSC (2007) } \\
\cline { 2 - 10 } & CCC & CIC & \multicolumn{2}{|c|}{ Total } & CCF & CIC & \multicolumn{2}{c|}{ Total } \\
\hline Referências Nacionais & 1.272 & 208 & 1.480 & $\mathbf{5 9 , 5 \%}$ & 608 & 480 & 1.088 & $\mathbf{7 6 , 9 \%}$ \\
\hline Referências Internacionais & 881 & 125 & 1.006 & $\mathbf{4 0 , 5} \%$ & 270 & 56 & 326 & $\mathbf{2 3 , 1 \%}$ \\
\hline (a) Número de referências & $\mathbf{2 . 1 5 3}$ & $\mathbf{3 3 3}$ & $\mathbf{2 . 4 8 6}$ & & $\mathbf{8 7 8}$ & $\mathbf{5 3 6}$ & $\mathbf{1 . 4 1 4}$ & \\
\hline (b) Número de artigos & 100 & 20 & 120 & & 45 & 26 & 71 & \\
\hline $\begin{array}{l}\text { (a/b) Número médio de } \\
\text { referências }\end{array}$ & $\mathbf{2 1 , 5}$ & $\mathbf{1 6 , 7}$ & $\mathbf{2 0 , 7}$ & & $\mathbf{1 9 , 5}$ & $\mathbf{2 0 , 6}$ & $\mathbf{1 9 , 9}$ & \\
\hline
\end{tabular}

Fonte: Adaptado de GOMES et al.(2007).

Os dados dos Congressos USP e UFSC apresentam um percentual de obras nacionais maior do que o de obras internacionais. Entretanto, a literatura internacional é mais freqüente nos Congressos USP, que a referenciaram 17\% a mais. Cabe destacar que, entre as 1.006 obras internacionais, apenas, $6 \%$ são obras traduzidas. Os dados ilustrados na Tabela 4 mostram que, das referências utilizadas nos Congressos UFSC, a maior parte são obras nacionais, constando apenas $23 \%$ de referências internacionais. Esse resultado evidencia o baixo emprego da literatura estrangeira nos trabalhos produzidos. Cabe ressaltar que, dentre as 326 obras internacionais referenciadas nos Congressos UFSC, $9 \%$ são traduzidas.

(v) Tipo de referência: a Tabela 5 apresenta a distribuição dos tipos de referências utilizadas nos referidos congressos. 
Tabela 5 - Tipo de referência utilizada nos artigos dos Congressos USP e UFSC

\begin{tabular}{|c|c|c|c|c|c|c|c|c|c|}
\hline \multirow{2}{*}{\multicolumn{2}{|c|}{ Tipo de Bibliografia }} & \multicolumn{4}{|c|}{ Congressos USP (2004) } & \multicolumn{4}{|c|}{ Congressos UFSC (2007) } \\
\hline & & \multirow{2}{*}{$\begin{array}{l}\mathrm{CCC} \\
631\end{array}$} & \multirow{2}{*}{$\begin{array}{l}\mathrm{CIC} \\
108\end{array}$} & \multicolumn{2}{|c|}{ Total } & \multirow{2}{*}{$\begin{array}{l}\text { CCF } \\
284\end{array}$} & \multirow{2}{*}{$\begin{array}{l}\mathrm{CIC} \\
191\end{array}$} & \multicolumn{2}{|c|}{ Total } \\
\hline \multirow[b]{2}{*}{ Livros } & Nacional & & & 739 & $29,7 \%$ & & & 475 & $33,6 \%$ \\
\hline & $\begin{array}{l}\text { Internaciona } \\
\text { l }\end{array}$ & 247 & 83 & 330 & $13,3 \%$ & 98 & 28 & 126 & $8,9 \%$ \\
\hline \multirow{2}{*}{$\begin{array}{l}\text { Teses, Dissert. e } \\
\text { Monografias }\end{array}$} & Nacional & 128 & 14 & 142 & $5,7 \%$ & 62 & 26 & 88 & $6,2 \%$ \\
\hline & $\begin{array}{l}\text { Internaciona } \\
l\end{array}$ & 8 & - & 8 & $0,3 \%$ & 3 & - & 3 & $0,2 \%$ \\
\hline \multirow{2}{*}{$\begin{array}{l}\text { Periódicos } \\
\text { Qualis/Capes }\end{array}$} & Nacional & 82 & 9 & 91 & $3,7 \%$ & 53 & 44 & 97 & $6,7 \%$ \\
\hline & $\begin{array}{l}\text { Internaciona } \\
\text { I }\end{array}$ & 222 & 29 & 251 & $10,1 \%$ & 66 & 7 & 73 & $5,2 \%$ \\
\hline \multirow{2}{*}{$\begin{array}{l}\text { Anais de Eventos } \\
\text { Científicos }\end{array}$} & Nacional & 70 & 8 & 78 & $3,1 \%$ & 38 & 51 & 89 & $6,3 \%$ \\
\hline & $\begin{array}{l}\text { Internaciona } \\
\text { l }\end{array}$ & 14 & - & 14 & $0,6 \%$ & 11 & - & 11 & $0,8 \%$ \\
\hline \multirow[b]{2}{*}{ Sites da Web } & Nacional & 147 & 40 & 187 & $7,5 \%$ & 97 & 137 & 234 & $16,6 \%$ \\
\hline & Internaciona & 77 & 10 & 87 & $3,5 \%$ & 9 & 4 & 13 & $0,9 \%$ \\
\hline \multirow{2}{*}{$\begin{array}{l}\text { Jornais e } \\
\text { Revistas }\end{array}$} & Nacional & 74 & 7 & 81 & $3,3 \%$ & 22 & 12 & 34 & $2,4 \%$ \\
\hline & $\begin{array}{l}\text { Internaciona } \\
\text { l }\end{array}$ & 232 & - & 232 & $9,3 \%$ & 70 & 12 & 82 & $5,8 \%$ \\
\hline \multirow[b]{2}{*}{ Normas } & Nacional & 71 & 6 & 77 & $3,1 \%$ & 35 & 3 & 38 & $2,7 \%$ \\
\hline & $\begin{array}{l}\text { Internaciona } \\
\text { l }\end{array}$ & 4 & 1 & 5 & $0,2 \%$ & - & - & - & - \\
\hline \multirow[b]{2}{*}{ Outros } & Nacional & 69 & 16 & 85 & $3,4 \%$ & 17 & 16 & 33 & $2,4 \%$ \\
\hline & $\begin{array}{l}\text { Internaciona } \\
l\end{array}$ & 77 & 2 & 79 & $3,2 \%$ & 13 & 5 & 18 & $1,3 \%$ \\
\hline Total & & 2.153 & 333 & 2.486 & $100,0 \%$ & 878 & 536 & $\begin{array}{c}1.41 \\
4\end{array}$ & $100,0 \%$ \\
\hline
\end{tabular}

Fonte: Adaptado de GOMES et al.(2007).

Nos Congressos USP, a categoria conservadora é a mais utilizada, sendo os livros as obras mais referenciadas, com $43 \%$ de freqüência no total das referências. Já na categoria contemporânea, o destaque é para os Jornais e Revistas $(12,6 \%)$, que incluem os periódicos não classificados no Qualis-Capes. A categoria intermediária segue em terceiro lugar, com $14 \%$ de freqüência. Nos Congressos UFSC, observa-se que, do total de referências, a categoria conservadora também é a mais utilizada, destacando-se os livros $(42,5 \%)$ como fonte de pesquisa mais referenciada. Nas fontes de pesquisas contemporâneas, o destaque é para os sites da Web, com $17,5 \%$ de freqüência nas bibliografias analisadas. A categoria intermediária, que inclui os periódicos classificados no Qualis/Capes, representa $12 \%$.

(vi) Número de autores por artigo: a Tabela 6 relaciona o número de autores por artigo, evidenciado o total de participações e o número médio de autores em cada congresso. 
Tabela 6 - Número de autores por artigo nos Congressos USP e UFSC

\begin{tabular}{|c|c|c|c|c|c|c|c|c|}
\hline \multirow{3}{*}{$\begin{array}{l}\text { Número de autores } \\
1 \text { autor }\end{array}$} & \multicolumn{4}{|c|}{ Congressos USP (2004) } & \multicolumn{4}{|c|}{ Congressos UFSC (2007) } \\
\hline & \multirow{2}{*}{$\begin{array}{c}\mathrm{CCC} \\
11\end{array}$} & \multirow{2}{*}{$\begin{array}{c}\mathrm{CIC} \\
1\end{array}$} & \multicolumn{2}{|c|}{ Total } & \multirow{2}{*}{$\frac{\mathrm{CCF}}{4}$} & \multirow{2}{*}{$\frac{\mathrm{CIC}}{1}$} & \multicolumn{2}{|c|}{ Total } \\
\hline & & & 12 & $10,0 \%$ & & & 5 & $7,0 \%$ \\
\hline 2 autores & 36 & 14 & 50 & $41,7 \%$ & 12 & 8 & 20 & $28,2 \%$ \\
\hline 3 autores & 30 & 1 & 31 & $25,8 \%$ & 14 & 5 & 19 & $26,8 \%$ \\
\hline 4 autores & 23 & 3 & 26 & $21,7 \%$ & 15 & 3 & 18 & $25,4 \%$ \\
\hline 5 autores & - & 1 & 1 & $0,8 \%$ & - & 3 & 3 & $4,2 \%$ \\
\hline 6 autores & - & - & - & - & - & 6 & 6 & $8,4 \%$ \\
\hline (a) Total de participações & 265 & 49 & 314 & & 130 & 95 & 225 & \\
\hline (b) Total de artigos & 100 & 20 & 120 & & 45 & 26 & 71 & \\
\hline $\begin{array}{l}\text { (a/b) Média de autores por } \\
\text { Artigo }\end{array}$ & 2,7 & 2,5 & 2,6 & & 2,9 & 3,7 & 3,2 & \\
\hline Total de autores & 200 & 47 & & & 98 & 75 & & \\
\hline
\end{tabular}

Fonte: Adaptado de GOMES et al.(2007).

Com relação ao número de autores por artigo nos Congressos USP, verifica-se que dentre os 120 artigos analisados, apenas 10\% são artigos produzidos por um autor e os outros 108 artigos são produzidos em co-autoria, sendo que a maioria envolve dois autores $(41,7 \%)$. Cabe destacar que, no CIC-USP, o percentual de artigos com dois autores é de $70 \%$, o que caracteriza a produção em co-autoria com o orientador de monografia ou de pesquisa de iniciação científica. Nos Congressos UFSC, 7\% dos artigos referem-se a trabalhos de um autor, enquanto que os 66 artigos restantes contaram com a participação de mais de um autor. No CCF-UFSC, a maior parte dos artigos produzidos $(33,3 \%)$ teve a participação de quatro autores. Já no CIC-UFSC, verifica-se uma freqüência maior de artigos com dois autores (30,8\%), o que sugere que esses artigos foram produzidos em coautoria com o orientador de monografia ou de pesquisa de iniciação científica. Observa-se que a ocorrência de artigos com seis autores apenas se fez presente no CIC-UFSC, totalizando $23 \%$ dos artigos, sendo que a maioria desses trabalhos pertence à UFPE.

(vii) Gênero dos autores: a Tabela 7 apresenta a predominância do gênero (feminino e masculino) dos autores em cada congresso.

Tabela 7 - Gênero dos autores nos Congressos USP e UFSC

\begin{tabular}{|l|c|c|c|c|c|c|c|c|}
\multirow{2}{*}{ Gênero } & \multicolumn{4}{|c|}{ Congressos USP (2004) } & \multicolumn{4}{c|}{ Congressos UFSC (2007) } \\
\cline { 2 - 9 } & \multicolumn{2}{|c|}{ CCC } & \multicolumn{2}{|c|}{ CIC } & \multicolumn{2}{c|}{ CCF } & \multicolumn{2}{|c|}{ CIC } \\
\hline Feminino & 68 & $\mathbf{3 4 , 0} \%$ & 20 & $\mathbf{4 2 , 6 \%}$ & 37 & $\mathbf{3 7 , 8 \%}$ & 51 & $\mathbf{6 8 , 0 \%}$ \\
\hline Masculino & 132 & $\mathbf{6 6 , 0} \%$ & 27 & $\mathbf{5 7 , 4} \%$ & $\mathbf{6 1}$ & $\mathbf{6 2 , 2} \%$ & $\mathbf{2 4}$ & $\mathbf{3 2 , 0} \%$ \\
\hline Total & $\mathbf{2 0 0}$ & & $\mathbf{4 7}$ & & $\mathbf{9 8}$ & & $\mathbf{7 5}$ & \\
\end{tabular}

Fonte: Adaptado de GOMES et al.(2007).

Com relação ao gênero dos autores nos Congressos USP, a Tabela 7 revela que tanto no CCC-USP quanto no CIC-USP prevalece a produção científica por autores do sexo masculino. A pesquisa revelou predominância dos autores do sexo masculino na produção científica do CCF-UFSC, com $62 \%$ de homens e $38 \%$ de mulheres participantes. Diferentemente, no CIC-UFSC prevalecem os autores do sexo feminino, com $68 \%$. 
(viii) Titulação dos autores: a Tabela 8 divide os autores pela titulação informada no currículo Lattes.

Tabela 8 - Titulação dos autores nos Congressos USP e UFSC

\begin{tabular}{|c|c|c|c|c|c|c|c|c|}
\hline \multirow{3}{*}{$\begin{array}{l}\text { Titulação } \\
\text { Não informada }\end{array}$} & \multicolumn{4}{|c|}{ Congressos USP (2004) } & \multicolumn{4}{|c|}{ Congressos UFSC (2007) } \\
\hline & \multicolumn{2}{|c|}{$\mathrm{CCC}$} & \multicolumn{2}{|c|}{$\mathrm{CIC}$} & \multicolumn{2}{|c|}{ CCF } & \multicolumn{2}{|c|}{$\mathrm{CIC}$} \\
\hline & 34 & $17,0 \%$ & 14 & $29,8 \%$ & 15 & $15,3 \%$ & 32 & $42,7 \%$ \\
\hline Graduação & 5 & $2,5 \%$ & 11 & $23,4 \%$ & 11 & $11,2 \%$ & 15 & $20,0 \%$ \\
\hline Especialização & 6 & $3,0 \%$ & 1 & $2,1 \%$ & 7 & $7,2 \%$ & - & - \\
\hline Mestrado & 62 & $31,0 \%$ & 8 & $17,0 \%$ & 31 & $31,6 \%$ & 12 & $16,0 \%$ \\
\hline Doutorado & 73 & $36,5 \%$ & 9 & $19,2 \%$ & 27 & $27,6 \%$ & 15 & $20,0 \%$ \\
\hline Pós-Doutorado & 12 & $6,0 \%$ & - & - & 6 & $6,1 \%$ & 1 & $1,3 \%$ \\
\hline Livre-Docência & 8 & $4,0 \%$ & 4 & $8,5 \%$ & 1 & $1,0 \%$ & - & - \\
\hline Total & 200 & $100,0 \%$ & 47 & $100,0 \%$ & 98 & $100,0 \%$ & 75 & $100,0 \%$ \\
\hline
\end{tabular}

Fonte: Adaptado de GOMES et al.(2007).

Os dados evidenciados destacam que, no CCC-USP, mais de $80 \%$ dos autores participantes possuem curso de pós-graduação. No CIC-USP, 23\% dos autores são da Graduação e 45\% são autores com Pós-graduação Stricto Sensu. Esses dados representam os trabalhos enviados por graduandos/graduados e seus orientadores. A Tabela 8 demonstra que, igualmente ao CCC-USP, o CCF-UFSC possui em maior número autores com Pósgraduação Stricto Sensu. Verifica-se, ainda, no CCF-UFSC, uma participação relevante dos autores da graduação, diferentemente do CCC-USP, o que demonstra a inserção de graduandos/graduados nos programas de pós-graduação. Em relação ao CIC-UFSC, os dados revelam a característica de um congresso de iniciação científica, tal qual no CIC-USP. 0 percentual de autores não cadastrados compromete a análise desse tópico.

(ix) Localização institucional dos autores: as Figuras 1 e 2 apresentam o percentual de autores que participaram nos Congressos USP e nos Congressos UFSC por região geográfica.

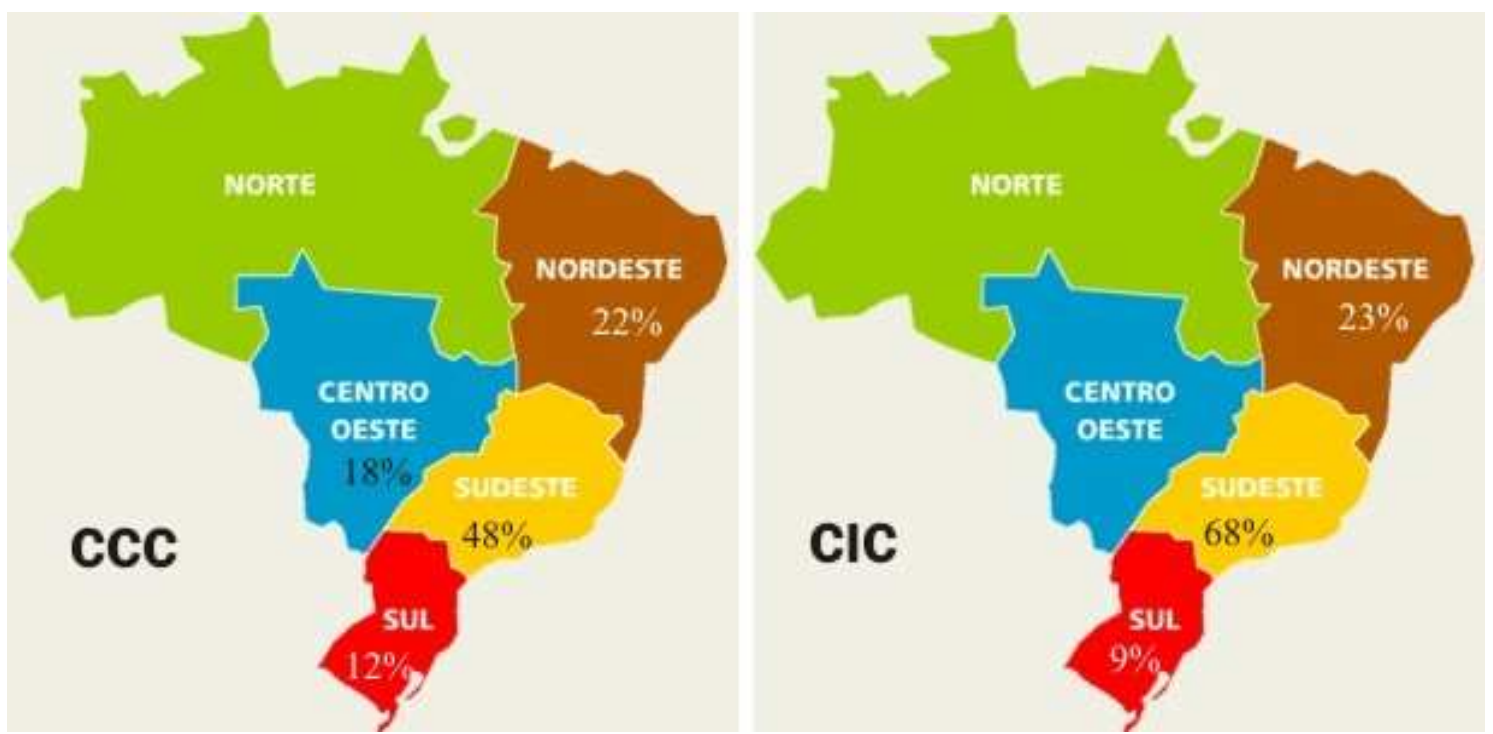

Figura 1 - Distribuição Geográfica dos autores nos Congressos USP 
A Figura 1 mostra que as regiões Sudeste e Nordeste, respectivamente, apresentam o maior número de autores participantes nos Congressos USP. Como era de se esperar, o Estado São Paulo, sede do evento, apresentou o maior número de autores nos dois congressos. Cabe destacar, também, a região Centro-Oeste, na qual o Distrito Federal teve o maior número de autores participantes no CCC-USP. Ressalta-se que, no CIC-USP, não houve a participação de autores da região Centro-Oeste, o que era esperado, já que nessa região insere-se a UNB.

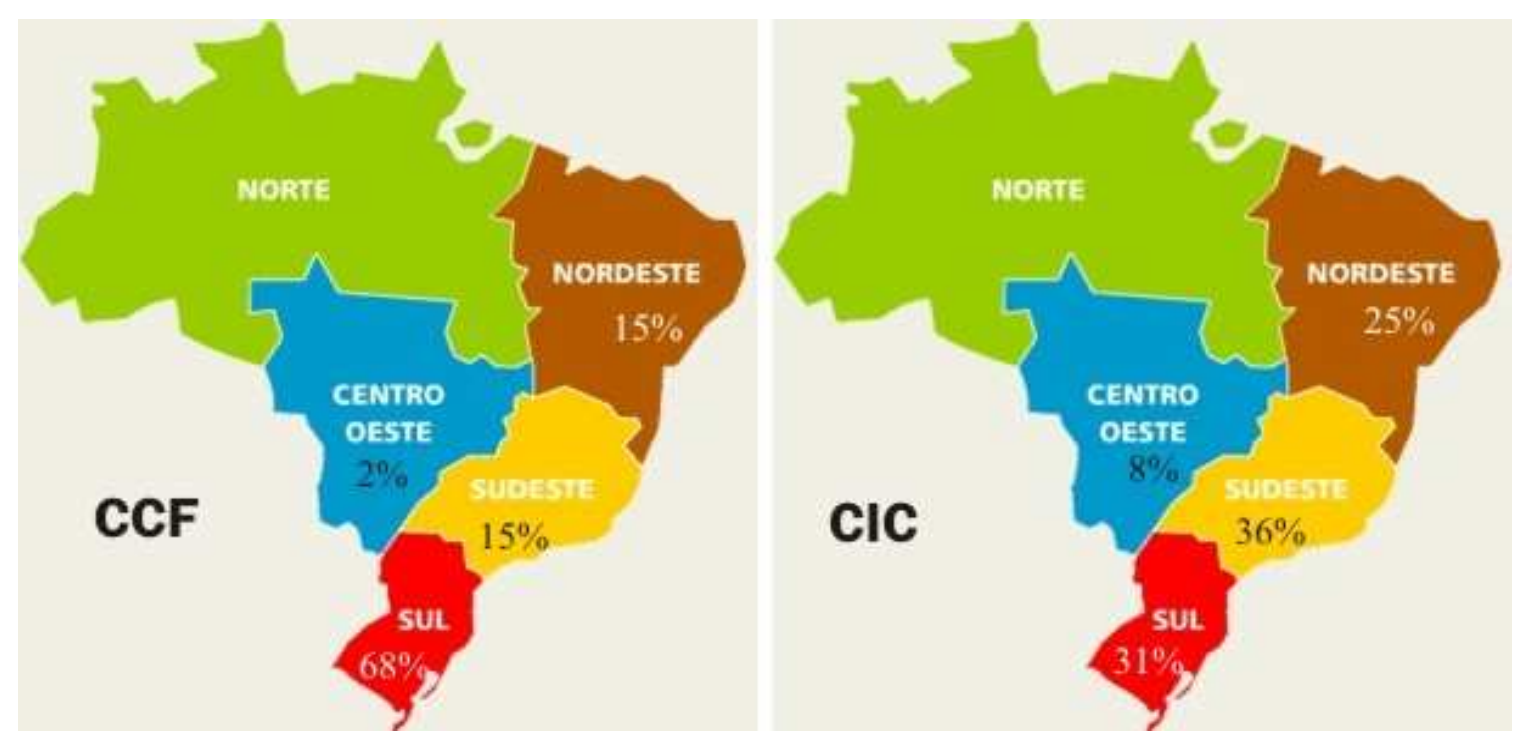

Figura 2 - Distribuição Geográfica dos autores nos Congressos UFSC

A Figura 2 revela que as regiões Sul, Sudeste e Nordeste apresentam o maior número de autores envolvidos nos Congressos UFSC. O Estado de Santa Catarina, sede do evento, teve o maior número de autores participantes. Em geral, a região Norte não apresentou contribuição nos quatro congressos analisados, o que é de se esperar, visto que a região não possui programas de pós-graduação na área contábil.

(x) Ranking dos autores por IES: observa-se, nessa análise, que as IES com maior participação de autores nos eventos analisados são a UFSC (95 participações) e a USP (92 participações), respectivamente. Porém, o maior número de autores concentra-se na USP, 65 autores, seguido da UFSC, com 61 autores. Nota-se que as IES em destaque são as instituições que sediam os eventos. Além dos autores da UFSC e da USP, destacam-se, a UFPE, com 66 participações e 34 autores, a UNB, com 41 participações e 30 autores, a UFU, com 28 autores participantes, contribuindo com 37 participações.

(xi) Aplicação da Lei de Lotka: a Tabela 9 apresenta a freqüência de artigos por autor em cada congresso analisado e no total da amostra, trazendo, ainda, a freqüência padrão de Lotka.

Tabela 9 - Freqüência do número de artigos por autor nos Congressos USP e UFSC 


\begin{tabular}{|l|c|c|c|c|c|c|}
\multirow{2}{*}{$\begin{array}{l}\text { Número de } \\
\text { artigos por } \\
\text { autor }\end{array}$} & \multicolumn{2}{|c|}{$\begin{array}{c}\text { Congressos USP } \\
\mathbf{( 2 0 0 4 )}\end{array}$} & \multicolumn{2}{c|}{$\begin{array}{c}\text { Congressos UFSC } \\
\mathbf{( 2 0 0 7 )}\end{array}$} & $\begin{array}{c}\text { Congressos } \\
\text { USP e UFSC }\end{array}$ & $\begin{array}{c}\text { Padrão de } \\
\text { Lotka }\end{array}$ \\
\cline { 2 - 5 } & CCC & CIC & CCF & CIC & & \\
\hline 1 artigo & $79,5 \%$ & $95,7 \%$ & $73,5 \%$ & $77,4 \%$ & $76,5 \%$ & $60,8 \%$ \\
\hline 2 artigos & $12,5 \%$ & $4,3 \%$ & $20,4 \%$ & $20,0 \%$ & $13,6 \%$ & $15,2 \%$ \\
\hline 3 artigos & $5,5 \%$ & - & $6,1 \%$ & $1,3 \%$ & $6,0 \%$ & $6,8 \%$ \\
\hline 4 artigos & $1,0 \%$ & - & - & $1,3 \%$ & $1,6 \%$ & $3,8 \%$ \\
\hline 5 artigos & $1,5 \%$ & - & - & - & $1,6 \%$ & $2,4 \%$ \\
\hline 6 artigos & - & - & - & - & $0,5 \%$ & $1,7 \%$ \\
\hline 7 artigos & - & - & - & - & $0,2 \%$ & $1,2 \%$ \\
\hline Mais de 7 artigos & - & - & - & - & - & $8,1 \%$ \\
\hline Total & $100,0 \%$ & $100,0 \%$ & $100,0 \%$ & $100,0 \%$ & $100,0 \%$ & $100,0 \%$ \\
\hline
\end{tabular}

Os dados da Tabela 9 revelam que a maioria dos autores publicou apenas um artigo, enquanto que uma minoria produziu mais de um artigo. Considerando os 383 autores que participaram dos quatro congressos, verifica-se que desses, $77 \%$ publicaram apenas um artigo, enquanto que apenas, $23 \%$ produziram mais de um artigo. Esses resultados, se comparados com o Padrão de Lotka, confirmam que alguns pesquisadores publicam muito, e muitos pesquisadores publicam poucos artigos. Contudo, verifica-se que os autores da amostra, que produzem mais do que um artigo, produzem menos do que o previsto por Lotka, como pode ser constatado no cotejamento das duas últimas colunas da Tabela 9 a partir da terceira linha.

(xii) Autores mais prolíficos: apresentam-se na Tabela 10 os macro-temas abordados pelos autores que publicaram três artigos ou mais nos eventos analisados. 


\begin{tabular}{|c|c|c|c|c|c|c|c|c|c|c|c|c|c|c|}
\hline Macro-Temas & 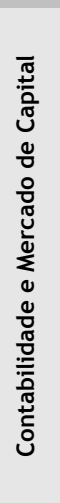 & 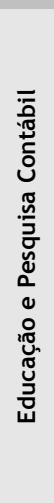 & 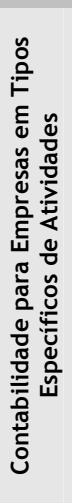 & 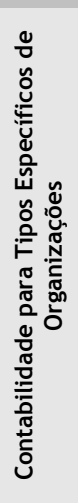 & 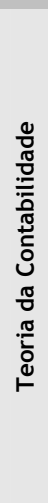 & 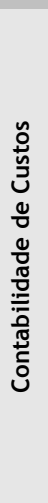 & 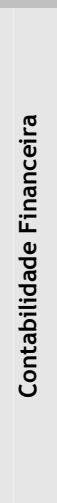 & 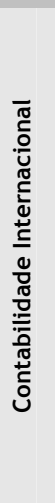 & 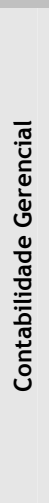 & 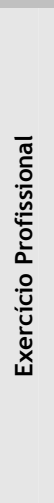 & 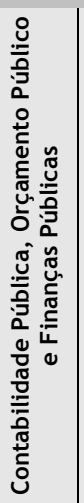 & 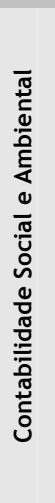 & 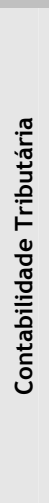 & 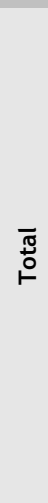 \\
\hline Sandra Rolim Ensslin & - & 4 & - & - & - & - & - & - & 2 & - & - & 1 & - & 7 \\
\hline José Francisco R. Filho & - & - & - & 1 & - & - & 1 & - & 2 & 1 & 1 & - & - & 6 \\
\hline Patrícia de Souza Costa & 1 & 3 & 1 & - & - & - & - & - & 1 & - & - & - & - & 6 \\
\hline Elisete D. Pfitscher & - & - & - & - & - & - & - & - & - & - & - & 5 & - & 5 \\
\hline Luiz Alberton & - & - & - & - & - & - & - & - & 1 & 1 & - & 2 & 1 & 5 \\
\hline Luiz João Corrar & 1 & 1 & - & 2 & - & - & 1 & - & - & - & - & - & - & 5 \\
\hline Maisa de Souza Ribeiro & - & - & - & - & - & - & 1 & - & - & - & - & 4 & - & 5 \\
\hline Otavio R. de Medeiros & 2 & - & - & - & - & - & - & - & 3 & - & - & - & - & 5 \\
\hline Raimundo N. Rodrigues & 3 & 1 & - & - & - & - & - & - & - & 1 & - & - & - & 5 \\
\hline Ana Elizabeth Araújo de Lima & 1 & - & - & - & - & - & - & - & 2 & 1 & - & - & - & 4 \\
\hline Jeronymo J. Libonati & 1 & - & - & - & - & - & - & - & 2 & - & 1 & - & - & 4 \\
\hline João Henrique $M$. de Albuquerque & 2 & 1 & - & - & - & - & - & - & 1 & - & - & - & - & 4 \\
\hline Paulo R. B. Lustosa & 3 & - & - & - & - & - & - & 1 & - & - & - & - & - & 4 \\
\hline Reinaldo Guerreiro & - & - & - & - & - & - & - & - & 4 & - & - & - & - & 4 \\
\hline Valcemiro Nossa & - & - & - & - & - & - & 1 & - & 2 & - & - & 1 & - & 4 \\
\hline Adriana R. Fragoso & - & - & - & 1 & - & - & 1 & - & - & - & 1 & - & - & 3 \\
\hline Alberto S. Matsumoto & 3 & - & - & - & - & - & - & - & - & - & - & - & - & 3 \\
\hline Aldemar de A. Santos & 1 & 1 & - & - & - & - & - & - & - & 1 & - & - & - & 3 \\
\hline Alessandra V. Gallon & - & - & - & - & - & - & - & - & 1 & - & - & 2 & - & 3 \\
\hline Altair Borgert & - & - & - & - & - & - & - & - & 3 & - & - & - & - & 3 \\
\hline Antonio Lopo Martinez & 1 & - & - & - & - & - & 1 & - & 1 & - & - & - & - & 3 \\
\hline Aridelmo J. C. Teixeira & 1 & - & - & - & - & - & 1 & - & 1 & - & - & - & - & 3 \\
\hline Carlos A. Pereira & - & - & - & 1 & - & - & - & - & - & - & - & - & 2 & 3 \\
\hline César M. Cupertino & 3 & - & - & - & - & - & - & - & - & - & - & - & - & 3 \\
\hline Charles A. Schultz & - & - & - & - & - & - & - & - & 3 & - & - & - & - & 3 \\
\hline Eleonora Milano Falcão Vieira & - & - & - & - & - & - & - & - & - & - & - & 3 & - & 3 \\
\hline Fábio Moraes da Costa & 1 & - & - & 1 & - & - & - & - & 1 & - & - & - & - & 3 \\
\hline Gilberto de A. Martins & - & 2 & - & - & 1 & - & - & - & - & - & - & - & - & 3 \\
\hline Hugo I. F. Santiago & - & 1 & - & - & - & - & - & - & 2 & - & - & - & - & 3 \\
\hline Jorge Expedito de Gusmão Lopes & 1 & 1 & - & - & - & - & - & - & - & - & 1 & - & - & 3 \\
\hline José Odálio dos Santos & 3 & - & - & - & - & - & - & - & - & - & - & - & - & 3 \\
\hline Luiz N. G. de Carvalho & - & - & - & - & - & - & - & 2 & 1 & - & - & - & - & 3 \\
\hline Marcelle C. Oliveira & - & - & - & - & - & - & 1 & - & - & - & - & 2 & - & 3 \\
\hline Marcia S. A. Sampaio & - & - & - & - & - & - & 1 & - & - & - & - & 2 & - & 3 \\
\hline Paulo Sergio Ceretta & 2 & - & - & - & - & 1 & - & - & - & - & - & - & - & 3 \\
\hline Sirlei Lemes & 1 & - & - & - & - & - & - & 2 & - & - & - & - & - & 3 \\
\hline Valdirene Gasparetto & - & - & - & - & - & - & - & - & - & - & - & 3 & - & 3 \\
\hline Valmor Slomski & - & 1 & - & - & - & - & 1 & 1 & - & - & - & - & - & 3 \\
\hline Total & 31 & 16 & 1 & 6 & 1 & 1 & 10 & 6 & 33 & 5 & 4 & 25 & 3 & 142 \\
\hline
\end{tabular}


Observa-se que, das trinta e oito posições ocupadas pelos autores mais prolíficos, elencadas na Tabela 10, nove estão vinculadas à UFPE, oito pertencem à UFSC e sete estão vinculadas à USP. Nessa análise, verifica-se que dentre os trinta e oito autores, apenas o Prof. Dr. José Francisco Ribeiro Filho (UFPE), com 6 artigos produzidos, publicou nos quatro congressos analisados. Destaca-se, também, a autora Profa. Dra. Sandra Rolim Ensslin (UFSC), que publicou 7 artigos, sendo 4 em co-autoria no CIC-UFSC, como orientadora, o que demonstra seu incentivo à iniciação científica. Observa-se, que os temas Contabilidade Gerencial, Contabilidade e Mercado de Capital e Contabilidade Social e Ambiental, respectivamente, foram os mais explorados pelos autores. É curioso que o tema Teoria da Contabilidade tenha apresentado poucos artigos, dado a importância do estudo epistemológico de uma ciência. Os macro-temas História da Contabilidade, Auditoria Externa e Interna e Perícia Contábil não apresentaram artigos publicados pelos autores mais prolíficos.

\section{CONSIDERAÇÕES FINAIS}

Este trabalho teve como objetivo geral sistematizar a produção científica dos Congressos USP de Controladoria e Contabilidade e Iniciação Científica em Contabilidade (2004) e compará-los com a produção dos Congressos UFSC de Controladoria e Finanças e Iniciação Científica em Contabilidade (2007). Por serem esses eventos sediados por seus departamentos de contabilidade e, principalmente, por apresentarem a modalidade "Iniciação Científica". No intuito de conhecer as características dessas produções e as de seus autores, fez-se uso de um estudo bibliométrico com base nos dados extraídos dos 191 artigos provenientes dos 383 autores.

Os dados ora levantados trazem como primeiro resultado das características das publicações, o número de página por artigos. Tendo em vista que os quatro congressos apresentam o mesmo limite de páginas por artigo, verifica-se que os autores dos Congressos USP aproveitaram mais o limite máximo disponível. Quanto à tipologia de pesquisa adotada, prevalece o estudo empírico-teórico nos Congressos USP e UFSC. As análises quanto aos macro-temas abordados revelou a importância, nos Congressos USP, dos macro-temas Contabilidade e Mercado de Capital, enquanto que, nos Congressos UFSC, o destaque foi para Contabilidade Gerencial. Com relação ao número de referências, nos congressos analisados, a maior parte são obras nacionais, o que evidencia o baixo emprego da literatura estrangeira nos trabalhos produzidos. Considerando o tipo de referência mais utilizado, verifica-se que a categoria conservadora é a mais freqüente nos quatro congressos, sendo os livros as obras mais referenciadas. Quanto ao número de autores por artigo nos Congressos USP, verifica-se que a maioria envolve dois autores. Cabe destacar que, no CIC-USP, o maior número de artigos envolve dois autores, o que caracteriza a produção em co-autoria com o orientador de monografia ou de pesquisa de iniciação científica. Ressalta-se, porém, que no CIC-UFSC, a maioria dos artigos apresenta mais de dois autores.

Nas análises das características de autorias, verifica-se, quanto ao gênero dos autores, que nos Congressos USP prevalecem a produção científica por autores do sexo masculino. Já nos Congressos UFSC, a pesquisa revelou predominância dos autores do sexo masculino no CCF-UFSC, enquanto no CIC-UFSC prevalecem os autores do sexo feminino. Com relação à titulação acadêmica dos autores, os dados destacam que no CCC-USP, igualmente ao CCF-UFSC, há em maior número autores com Pós-graduação Stricto Sensu. Em relação ao CIC-USP, os dados revelam a característica de um congresso de iniciação científica, tal qual no CIC-UFSC, ou seja, a maioria dos trabalhos foi enviada por graduandos/graduados e seus orientadores. Na observação da localização institucional dos 
autores, verificam-se as regiões Sudeste e Nordeste, respectivamente, com maior número de autores participantes nos Congressos USP; em contrapartida, nos Congressos UFSC, aparecem as regiões Sul, Sudeste e Nordeste. Constata-se, na análise do ranking dos autores por IES, que as instituições com maior participação de autores são a UFSC, USP, UFPE, UNB e a UFU. Na tentativa de comparar a produtividade dos autores com o padrão de Lotka, observa-se que os autores da amostra em questão produzem menos do que o previsto por Lotka. Na identificação dos autores mais prolíficos, observa-se que maior parte desses autores está vinculada à UFPE, USP e UFSC. Na contribuição dos autores mais prolíficos por classificação temática, apresentam-se os macro-temas Contabilidade Gerencial, Contabilidade e Mercado de Capital e Contabilidade Social e Ambiental, respectivamente.

O levantamento realizado limitou-se à análise pontual no tempo. O Congresso USP de Controladoria e Contabilidade teve seu evento inicial em 2001, porém para fins desta pesquisa foram analisadas as publicações do ano de 2004, ou seja, o $4^{\circ}$ Congresso USP de Controladoria e Contabilidade considerando nesse período, o início do $1^{\circ}$ Congresso USP de Iniciação Científica para fins de comparação com os Congressos UFSC. Mostra-se relevante - levantamento das características dessas publicações e de seus autores para se conhecer o perfil e o desenvolvimento das pesquisas em contabilidade, principalmente, no que tange a iniciação científica. Como sugestões para futuros trabalhos propõem-se a expansão desta pesquisa aos anos subseqüentes dos Congressos USP objetivando traçar uma evolução dos aspectos analisados. Outro aspecto interessante é observar se os alunos da amostra em questão ingressaram em cursos de pós-graduação. Por último, sugere-se a investigação da participação de alunos da graduação em outros eventos científicos de contabilidade.

\section{REFERÊNCIAS}

ALVARADO, Rubén Urbizagástegui. A lei de lotka na bibliometria brasileira. Ciência da Informação, Brasília, v. 31, n. 2, p. 14-20, maio/ago. 2002. Disponível em: <http://www.ibict.br/cionline/>. Acesso em: 26 dez. 2007.

BEUREN, Ilse Maria. Como elaborar trabalhos monográficos em contabilidade. 3. ed. São Paulo: Atlas, 2006.

BUFREM, Leilah; PRATES, Yara. O saber científico registrado e as práticas de mensuração da informação. Ciência da Informação, Brasília, v. 34, n. 2, p. 9-25, maio/ago. 2005. Disponível em: <http://www.ibict.br/cionline/>. Acesso em: 5 ago. 2007.

CABRAL DOS SANTOS, Maike; ENSSLIN, Sandra Rolim. Goodwill: uma análise a partir dos artigos publicados nos principais congressos nacionais de contabilidade no período de 2000 a 2006. In: CONGRESSO UFSC DE INICIAÇÃO CIENTÍFICA EM CONTABILIDADE, 1, Florianópolis. Anais... Florianópolis: UFSC, 2007. 14 p. CD-ROM.

CARDOSO, Ricardo Lopes, et al. Pesquisa científica em contabilidade entre 1990 e 2003. Revista de Administração de Empresas, São Paulo, v. 45, n. 2, p. 34-45, abr./jun. 2005. Disponível em: <http://www.rae.com.br/>. Acesso em: 10 out. 2007.

GOMES, Rafael Barbosa, et al. Um estudo sobre a produção acadêmica em contabilidade: uma abordagem nos Congressos USP de Iniciação Científica em Contabilidade. In: CONGRESSO USP DE INICIAÇÃOO CIENTÍFICA EM CONTABILIDADE, 4, 2007, São Paulo. Anais... Disponível em: <http://www.congressoeac.locaweb.com.br/Artigos72007>. Acesso em: 8 ago. 2007. 
FACULDADE DE ECONOMIA, ADMINISTRAÇÃO E CONTABILIDADE DA USP. Congresso USP. $5^{\circ}$ Congresso USP de Iniciação Científica em Contabilidade. Disponível em: <http://www.congressoeac.locaweb.com.br/principal.asp>. Acesso em: 10 jan. 2008.

GUEDES, Vânia L. S.; BORSCHIVER, Suzana. Bibliometria: uma ferramenta estatística para a gestão da informação e do conhecimento, em sistemas de informação, de comunicação e de avaliação científica e tecnológica. In: ENCONTRO NACIONAL DE CIÊNCIA DA INFORMAÇÃ̂O, 6, 2005, Salvador. Anais... Disponível em: <http://www.cinform.ufba.br/vi_anais/>. Acesso em: 10 out. 2007.

LEAL, Ricardo Pereira Câmara; OLIVEIRA, Jefferson de; SOLURI, Aline Feldman. Perfil da pesquisa em finanças no Brasil. Revista de Administração de Empresas, São Paulo, v. 43, n. 1, p. 91-104, jan./mar.2003. Disponível em: <http://www.rae.com.br/>. Acesso em: 10 out. 2007.

LEITE FILHO, Geraldo Alemandro. Padrões de produtividade de autores em periódicos e congressos na área de contabilidade no Brasil: um estudo bibliométrico. In: CONGRESSO USP DE CONTROLADORIA E CONTABILIDADE, 6., 2006, São Paulo. Anais... Disponível em: <http://www.congressoeac.locaweb.com.br/artigos62006/>. Acesso em: 8 ago. 2007.

MACEDO DOS SANTOS, Raimundo Nonato. Produção científica: por que medir? 0 que medir? Revista Digital de Biblioteconomia e Ciência da Informação, Campinas, v. 1, 1, p. 22-38, jul./dez., 2003. Disponível em: <http://server01.bc.unicamp.br/seer/ojs/index.php>. Acesso em: 5 ago. 2007.

MARCONI, Marina de Andrade; LAKATOS, Eva Maria. Metodologia científica. 5. ed. São Paulo: Atlas, 2007.

OLIVEIRA, Antônio Benedito Silva et al. Métodos e técnicas de pesquisa em contabilidade. São Paulo: Saraiva, 2003.

OLIVEIRA, Marcelle Colares. Análise dos Periódicos brasileiros de contabilidade. Revista Contabilidade \& Finanças, São Paulo, n. 29, p. 68-86, maio/ago. 2002. Disponível em: <http://www.eac.fea.usp.br/eac/revista/>. Acesso em: 10 out. 2007.

RICHARDSON, Roberto Jarry. Pesquisa social: métodos e técnicas. 3. ed. São Paulo: Atlas, 1999.

VANTI, Nadia Aurora Peres. Da bibliometria à webometria: uma exploração conceitual dos mecanismos utilizados para medir o registro da informação e a difusão de conhecimento. Ciência da Informação, Brasília, v. 31, n. 2, p. 152-162, maio/ago. 2002. Disponível em: <http://www.ibict.br/cionline/>. Acesso em: 5 ago. 2007. 